\title{
Absence of detectable local antibody in genitourinary tract secretions of male contacts of women infected with Trichomonas vaginalis
}

\author{
J. P. ACKerS, R. D. CATterall, W. H. R. LUMSDEN, AND A. MCMILLAN* \\ From the Department of Medical Protozoology, London School of Hygiene and Tropical Medicine; \\ James Pringle House, Middlesex Hospital, London; and the Royal Infirmary, Edinburgh
}

SUMMARY Samples of semen and urine were obtained from 37 male contacts of women with proved Trichomonas vaginalis infection; on culture, eight $(22 \%)$ of the men were shown to harbour the parasite. However, significant amounts of antitrichomonal antibody were found in only two of these samples, and the amounts present were very small. A further 10 samples were tested but none was found to contain antibody. The asymptomatic nature and low parasite numbers commonly described in infections in men is thus unlikely to be due to a vigorous local immune response.

\section{Introduction}

We have already demonstrated the presence of specific antitrichomonal antibody in the vaginal secretions of about $75 \%$ of a group of infected women as well as in $40 \%$ of a small group of controls (Ackers et al., 1975). Previously, Chipperfield and Evans (1972) showed an increase in the number of immunoglobulin-bearing plasma cells in cervical biopsies, not only from women with gonorrhoea, trichomoniasis, and candidosis, but also in biopsies from women who had been exposed to Neisseria gonorrhoeae but who had not apparently become infected. Although it is believed that most cases of trichomoniasis are sexually transmitted (Catterall and Nicol, 1960), the parasite is usually difficult to demonstrate in the male. We therefore decided to examine various secretions from men who had been in recent contact with women with proved trichomoniasis to see if any evidence of local antibody production could be found.

\section{Materials and methods}

\section{SAMPLES}

Three types of specimen were collected-semen and urine from patients at James Pringle House, Middle-

Address for reprints: Dr J. P. Ackers, Department of Medical Protozoology, London School of Hygiene and Tropical Medicine, Keppel Street, London WC1E 7HT

*Present address: Black Street Clinic, The Royal Infirmary, Glasgow Received for publication 23 November 1977 sex Hospital, London, and semen and urethral secretions from patients attending the Department of Venereology, Royal Infirmary, Edinburgh.

\section{Samples collected in London}

Women with proved trichomoniasis were asked to invite their male contacts to attend. In all cases trichomoniasis was diagnosed by wet-film examination and confirmed by culture. Those men who did attend were given a routine examination and a urine sample was collected. They were then asked if they would provide a specimen of semen, either at the clinic or in their own homes. Those who chose the latter were asked to bring the specimen to the clinic with the minimum possible delay. Samples of semen and midstream urine were collected from the clinic twice a day, centrifuged ( $1000 \mathrm{~g}$ for $10 \mathrm{~min}$ ) and the supernatants stored at $-20^{\circ} \mathrm{C}$. Sediments were examined by wet film and culture for the presence of T. vaginalis.

\section{Samples collected in Edinburgh}

The procedure was similar to that employed in London, all male contacts who attended being referred to one of the authors (AM). To collect urethral secretions, $2 \mathrm{ml}$ of sterile phosphatebuffered saline were instilled into the distal urethra by means of a soft polyethylene tube. After allowing 60 seconds for equilibration with urethral secretions, the saline was collected in a sterile bijou bottle. If patients agreed, semen samples were collected at the clinic. Examination, centrifugation, and culture were 
carried out at the clinic; samples were sent, at $-80^{\circ} \mathrm{C}$, to London for antibody assay.

Procedures and medium used for culture were as previously described (Ackers et al., 1975) except that, in view of the paucity of organisms expected, cultures were kept at $37^{\circ} \mathrm{C}$ for 14 days before being discarded.

\section{ANTIBODY ASSAY}

Preparation of ${ }^{125}$ I-labelled antihuman IgA and its use in the antibody assay were as previously described (Ackers et al., 1975), modified slightly to eliminate the high values previously discussed for counts bound in the absence of antibody.

In the previous assay, each woman's secretion was assayed against her own isolate of $T$. vaginalis; however, this was not possible in this case since most of the men were culturally negative. To overcome this problem, and to make the assay more reproducible, a mixed antigen was prepared. Twelve strains, obtained from both London and Edinburgh, were grown in bulk and the harvested organisms washed and pooled. The organisms were then suspended in a mixture of inactivated calf serum (Wellcome) $(10 \% \mathrm{v} / \mathrm{v})$ and dimethylsulphoxide (Analar) $(10 \% \mathrm{v} / \mathrm{v})$ in phosphate-buffered isotonic saline, pH 7.2 (PBS) at a count of $5 \times 10^{6}$ organisms/ $\mathrm{ml}$ and divided into $1 \mathrm{ml}$ aliquots. These were then slowly cooled at $-80^{\circ} \mathrm{C}$ and stored until required. After thawing, up to half the organisms were still visibly motile; they were washed three times with PBS, adjusted to $5 \times 10^{6}$ organisms $/ \mathrm{ml}$ and used in the assay as previously described.

As before, antibody in the samples is expressed as counts per minute (cpm) bound. The significance of differences observed was assessed by calculating $\mathbf{P}$ values (Swinscow, 1976).

\section{Results}

In the London study, 36 men who were contacts of 260 women with microscopically proved $T$. vaginalis infection attended. Urine specimens alone were obtained from six and semen and urine from the other 30.

Specimens of semen and urine were obtained from three further men who had attended unasked: one had been in contact with a woman who had trichomoniasis, while the other two had frank urethral discharge and were shown by wet-film examination to be infected with $T$. vaginalis. Results of tests on these two men with symptomatic infection are presented separately at the end of this section.

Microscopical examination of sediments of semen and urine from the 37 contacts was uniformly negative, but $T$. vaginalis was cultured from eight $(22 \%)$ of the men-from semen alone in two cases, from urine alone in two, and from both semen and urine in the four others.

Of the 37 men in contact with infected women, three (including two shown to be infected with $T$. vaginalis) were already attending James Pringle House for the treatment of other complaints. Of the remaining $34 \mathrm{men}$, three (none apparently infected) had mild symptoms (urethral discharge, discharge and dysuria, and frequency respectively) and one, infected with $T$. vaginalis, was initially diagnosed as suffering from non-specific urethritis. The remainder (including five with proved infections) were completely asymptomatic.

An attempt was made to assess the degree of infection of the female partners of the men exposed to infection by counting the number of organisms in $10 \times 400$ fields of the initial wet film. Of the 260 women scored, 242 had a mean of 2.53 organisms/ field (SD 2.433$)$, while $18(6.9 \%)$ had very significantly $(0.001<\mathrm{P}<0.003)$ higher scores (more than 10 organisms/field). The scores of 34 of the women whose contacts came forward were available: they had a mean of 1.85 (SD 2.1) organisms/field, not significantly different from the rest of the women. Two $(5.8 \%)$ of these 34 women had high ( $>10$ organisms/field) scores, but neither had apparently infected her partner.

The Edinburgh clinic yielded 10 semen samples from known male contacts of infected women; none contained $T$. vaginalis as judged by culture or wetfilm examination. A further nine samples, of semen and urethral secretions, were collected in Edinburgh from men who had no known contact with the parasite; $T$. vaginalis was not seen or cultivated from any of them.

Antitrichomonal antibody assays were performed on 23 semen and 14 urine samples from London contacts, and on all the Edinburgh samples. Results (mean cpm bound, corrected for radioactive decay) were: London, semen samples 216 (SD 161), urine samples 100 (SD 208); Edinburgh contacts 247 (SD 189); Edinburgh not in contact 270 (SD 297) (results from semen and urethral secretions were very similar, so have been combined). These mean values are not statistically different from one another, and all are far lower than the results found with vaginal secretions from infected women (Ackers et al., 1975). Among all the samples tested, only two semen (both from London) contained significant $(P<0.001)$ amounts of antibody (1521 and 1773 $\mathrm{cpm}): T$. vaginalis could not be isolated from either. The antibody content of those samples from which $T$. vaginalis was grown was not significantly higher or lower than that of the remaining ones. 
In the absence of sufficient quantity of any sample to act as a reference preparation, a 1:5 dilution of a standard serum (antitrichomonal agglutinin titre 1:2 to $1: 8)$ was included in each assay of the London samples. The mean counts bound for this standard from all the assays performed was $543 \mathrm{cpm}$ (SD 200), and all assays in which the standard result was less than 250 or greater than 800 were discarded. An attempt was also made to increase the reproducibility of the assay by multiplying the measured counts so as to bring the counts bound by the standard serum to 500 in all cases. These 'corrected' results, however, were not greatly different from the uncorrected ones -from London, semen $158 \mathrm{cpm}$ (SD 149), urine samples $112 \mathrm{cpm}$ (SD 216). Using 'corrected' figures, three semen samples now appeared with significant $(P<0.001)$ quantities of antibody - the original two (1845 and 1008 corrected cpm) and a third with 1138 corrected cpm.

Semen samples from the two men who presented with symptomatic trichomonal urethritis were also assayed: their content of antitrichomonal antibody (933 and 860 uncorrected cpm; 530 and 609 corrected cpm) was just significant $(0.01<\mathbf{P}<0.05)$.

\section{Discussion}

The first part of this study, although only for a small number of men, confirms previous reports that $T$. vaginalis is difficult to isolate from men with known exposure to the parasite, and that even men with culturally-proved infection are frequently asymptomatic. It seems that the few women who had large numbers of organisms in their vaginal secretions were not particularly likely to produce a frank infection in their partners.

Having previously shown (Ackers et al., 1975) that a significant number of infected women produced local antibody directed against this parasite, we wondered if the frequent absence of detectable infection in men was due to a similar local immune response. This, however, does not seem to be the case, for only two of our $\mathbf{4 4}$ men in contact had over $600 \mathrm{cpm}$ of bound antibody, and the results (1521 and $1773 \mathrm{cpm}$ ) were far below the average figure $(17900 \mathrm{cpm})$ previously found in antibody-producing women (Ackers et al., 1975). In view of the improvements made in the assay procedure, it seems unlikely that local antibody is produced by a significant number of male contacts, and, although the results from the two men with symptomatic infections were slightly above the average, they do not really suggest a vigorous immune response in progress.

An attempt was made to improve the reproducibility of the assay by relating all results to a common standard; results corrected by this procedure support the conclusions drawn from the uncorrected ones.

A large amount of work has been done on the immune response of the female genital tract to various antigens, largely stimulated by an interest in the immunological aspects of reproduction and fertility control (for a review, see Cinidar and de Weck, 1976). In contrast, the male genitourinary tract has received little attention. Rümke (1974) showed that most of the immunoglobulin in semen came from the prostate, and that, while the IgG appeared to be derived from serum, there was evidence for a small amount of local IgA synthesis. Kearns et al. (1973) showed the presence of antigonococcal antibody in the urethral exudate of men with uncomplicated gonorrhoea. Tapchaisri and Sirisinha (1976) confirmed this for some of the men they examined, but they also found that the antibody levels were much higher in women. Similarly, in a study of local antibody production in children with urinary-tract infections, Jodal et al. (1974) found that very little local IgA antibody against $E$. coli was produced by the small number of boys in the sample, although they emphasised that they were the youngest children in the group. Finally, it should be noted that, in contrast to cows, bulls infected with Trichomonas foetus produce very little, if any, antibody (Robertson, 1963), although local infection with Brucella abortus does lead to a local response (Christensen, 1948): this infection produces considerable inflammation and tissue destruction. The lack, in men, of a vigorous immune response to such a scanty and non-invasive parasite as $T$. vaginalis is thus perhaps not surprising, especially as it is not clear how long the organisms remain in the male urethra after infection. It is quite possible that the repeated passage of urine mechanically removes the parasite within a few days. Certainly we were able to isolate the organism from urine as well as from semen, and an investigation of the length of time men remain infected could perhaps be combined with a study of the possible value of a routine urine culture in diagnosis.

This work was supported by a Project Grant from the Medical Research Council to J. P. Ackers. We are grateful to Sister Coladangelo and her staff for counting the trichomonads in wet films, to the doctors from both centres for their co-operation, and to Miss Shirley Smith and Mrs Alison Matthews for technical assistance.

\section{References}

Ackers, J. P., Lumsden, W. H. R., Catterall, R. D., and Coyle, R. (1975). Antitrichomonal antibody in the vaginal secretions of women infected with Trichomonas vaginalis. British Journal of Venereal Diseases, 51, 319-323. 
Catterall, R. D., and Nicol, C. S. (1960). Is trichomonal infestation a venereal disease? British Medical Journal, 1, 1177-1179.

Chipperfield, E. J., and Evans, B. A. (1972). The influence of local infection on immunoglobulin formation in the human endo-cervix. Clinical and Experimental Immunology, 11, 219-223.

Christensen, N. O. (1948). Studies on the agglutinin formation in Brucellar infection of the genitals of the bull. Acta pathologica et microbiologica Scandinavica, 25, 202-209.

Cinidar, B., and de Weck, A., editors (1976). Immunological Response of the Female Reproductive Tract. Scriptor: Copenhagen.

Jodal, U., Ahlstedt, S., Carlsson, B., Hanson, L. A., Lindberg, U., and Sohl, A. (1974). Local antibodies in childhood urinary tract infection. International Archives of Allergy, 47, 537-546.
Kearns, D. H., O'Reilly, R. J., Lee, L., and Welch, B. G. (1973) Secretory IgA antibodies in the urethral exudate of men with uncomplicated urethritis due to Neisseria gonorrhoeae. Journal of Infectious Diseases, 127, 99-101.

Robertson, M. (1963). Antibody response in cattle to infection with Trichomonas foetus. In: Immunity to Protozoa, pp. 336-345. Edited by P. C. C. Garnham, A. E. Pierce, and I. Roitt. Blackwell: Oxford.

Rümke, P. (1974). The origin of immunoglobulins in semen. Clinical and Experimental Immunology, 17, 287-297.

Swinscow, T. D. V. (1976). Statistics at Square One, p. 21. British Medical Association: London.

Tapchaisri, P., and Sirisinha, S. (1976). Serum and secretory antibody responses to Neisseria gonorrhoeae in patients with gonococcal infections. British Journal of Venereal Diseases, 52, 374-380. 